\title{
A rare case of multiple digital infarcts in a patient with Mycobacterium avium-intracellulare (MAI) infection
}

\author{
Aneet Kaur, ${ }^{1}$ Jagpal Singh Klair, ${ }^{1}$ Yogita M Rochlani, ${ }^{1}$ Kevin Kuriakose, ${ }^{1}$ \\ Nasim A Khan ${ }^{2}$
}

${ }^{1}$ Department of Internal Medicine, University of Arkansas for Medical Sciences, Little Rock, Arkansas, USA ${ }^{2}$ Department of Rheumatology and Immunology, University of Arkansas for Medical Sciences, Little Rock, Arkansas, USA

\section{Correspondence to Dr Jagpal Singh Klair, klairjagpal@yahoo.com}

Accepted 20 March 2015

\section{CrossMark}

To cite: Kaur A, Klair JS,
Rochlani YM, et al. BMJ
Case Rep Published online:
[please include Day Month
Year] doi:10.1136/bcr-2015-
209582

\section{DESCRIPTION}

Granulomatosis with polyangitis (GPA) is an antineutrophil cytoplasmic antibodies (ANCA)-associated vasculitis that affects small-sized to medium-sized arteries, and usually involves the upper and lower respiratory tract, and kidneys. ${ }^{1}$ Digital gangrene can be an unusual feature of GPA. ${ }^{12}$ Pulmonary involvement can be in the form of multifocal or solitary lung lesions. ${ }^{1}$ This case describes a patient with ANCA-positive vasculitis, presenting with digital gangrene and cavitary lung lesions, along with a concomitant Mycobacterium avium-intracellulare (MAI) infection, in the absence of renal involvement.

A 59-year-old Caucasian woman presented with blackish discolouration of the fingertips on the right hand that started 3 weeks earlier (figure 1). She first noticed pallor, followed by erythema, cyanotic discolouration and, finally, dry gangrenous transformation of the fingertips. She denied any history of sinusitis, nasal discharge, cough, haemoptysis, or haematuria. Physical examination was remarkable for digital gangrene in multiple digits in the upper and lower extremities involving the distal phalangeal ends, and crackles on auscultation of the upper lung fields anteriorly. Laboratory work showed ANCA c (+), anti-nuclear antibodies (-), double-stranded DNA (-), anti- ribonuclear protein $(-)$, cold agglutinins $(-),+$ rheumatoid factor, high $\mathrm{C} 3$ and an elevated erythrocyte sedimentation rate. Chest X-ray and CT scan showed bilateral cavitary lesions in the lungs involving the upper lobes (figure 2). The patient was initially started on empiric broad-spectrum antibiotics for cavitary pneumonia.

The patient's laboratory work also showed acidfast bacilli $\times 2(+)$ for M. avium complex (MAC)

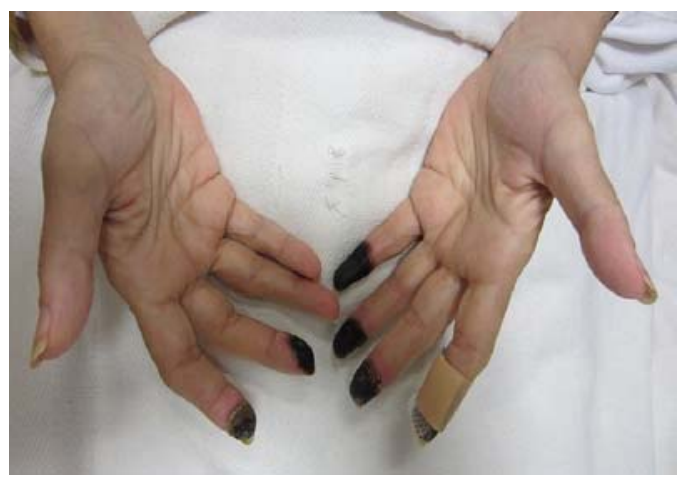

Figure 1 Multiple digital gangrene. and bronchoscopy with bronchoalveolar lavage (BAL) showed $(+)$ cultures for MAC. These findings, along with the cavitary lesions seen on the chest X-ray, were thought to be $2 / 2 \mathrm{MAI}$ infections. Rifabutin, ethambutol and azithromycin were started as therapy for MAI. The patient received treatment with macrolides for 12 months. She was followed with repeat chest X-rays at 6 and 12 months, with improvement in the cavitary lesions. For the digital gangrene, calcium channel blockers, antiplatelet agents and heparin were used. Additional laboratory results were positive for cytoplasmic ANCA (c-ANCA) (1:40).

CT of the chest showed bilateral cavitary lesions in the lungs involving the upper lobes, bilateral peribronchial opacities in lower lobes and no lymphadenopathy. This imaging, when correlated with clinical and laboratory work findings, was deemed consistent with GPA, and therapy with rituximab and high-dose methyl prednisone was initiated while inpatient, followed by outpatient rituximab infusions and prednisone taper. CT surgery was consulted and felt that biopsy of the cavitary areas would be very risky for bronchopleural fistula. So lung wedge biopsy was not performed, as no change in management was expected based on the biopsy findings. The patient underwent partial digit amputation of bilateral hand fingertips 2-4 digits.

Differential diagnosis for digital infarcts include primary vasculitis such as GPA, collagen vascular diseases such as lupus/scleroderma, leading to secondary vasculitis, septic embolism from acute bacterial endocarditis, cholesterol embolism, and hyperviscosity syndromes such as polycythaemia and Buerger's disease. ${ }^{1-3}$ GPA is more frequent in older adults and

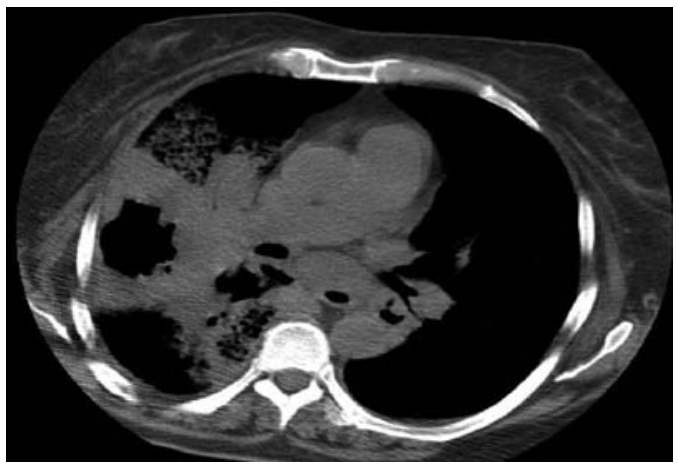

Figure 2 Right upper quadrant cavitary lesion seen on chest CT scan. 
Caucasians. Initial presentation usually includes fever, migratory arthralgias, malaise, anorexia and weight loss. ${ }^{2}$ It usually involves upper airways (sinusitis, otitis media, purulent nasal discharge),

\section{Learning points}

- Granulomatosis with polyangitis (GPA) usually involves the upper and lower respiratory tract, and kidneys, with rare occurrence of digital gangrene.

- Timely management is essential, but in the setting of a concomitant infection, treating the infection before initiating immunosuppressive therapy can help avoid adverse consequences.

- IV cyclophosphamide or rituximab and high-dose corticosteroids are used to induce remission. Mycobacterium avium-intracellulare infection has been associated with cytoplasmic antineutrophil cytoplasmic antibodies vasculitis. lower airways (cough, wheezing, consolidation), kidneys (asymptomatic haematuria, kidney injury) and skin (leukocytoclastic angitis). ${ }^{1}{ }^{3}$ c-ANCA is an immunological marker of GPA and biopsy of the lung or kidney is not essential for diagnosis or initiation of therapy. ${ }^{2}$ IV cyclophosphamide or rituximab and highdose corticosteroids are used to induce remission. ${ }^{3} \mathrm{MAI}$ infection has been associated with c-ANCA vasculitis.

Competing interests None declared.

Patient consent Obtained.

Provenance and peer review Not commissioned; externally peer reviewed.

\section{REFERENCES}

1 Agarwal A, Khan NA. Multiple digital gangrene and polyuria. Mayo Clin Proc 2012;87:e25.

2 Katzenstein ALA, Locke WK. Solitary lung lesions in Wegener's granulomatosis. Pathological findings and clinical significance in 25 cases. Am J Surg Pathol 1995;19:545-52.

3 Chaiamnuay S, Heck LW. Antineutrophil cytoplasmic antibody vasculitis associated with Mycobacterium avium intracellulare infection. J Rheumatology 2005;32:1610-12.

Copyright 2015 BMJ Publishing Group. All rights reserved. For permission to reuse any of this content visit http://group.bmj.com/group/rights-licensing/permissions.

BMJ Case Report Fellows may re-use this article for personal use and teaching without any further permission.

Become a Fellow of BMJ Case Reports today and you can:

- Submit as many cases as you like

- Enjoy fast sympathetic peer review and rapid publication of accepted articles

- Access all the published articles

- Re-use any of the published material for personal use and teaching without further permission

For information on Institutional Fellowships contact consortiasales@bmjgroup.com

Visit casereports.bmj.com for more articles like this and to become a Fellow 